\title{
Produção e avaliação físico-mecânica de painéis de média e alta densidade com resíduos
}

\author{
Physical-mechanical production and evaluation of medium \\ and high density waste panels
}

\begin{tabular}{|c|c|}
\hline & $\begin{array}{l}\text { Bruna Bessa Rocha Yano } \\
\text { Sérgio Augusto Mello da Silva (D) }\end{array}$ \\
\hline & $\begin{array}{l}\text { Resumo } \\
\begin{array}{l}\text { o Brasil intensificam-se os estudos visando ao aproveitamento de } \\
\text { serragem proveniente de processos industriais para a produção de } \\
\text { painéis de madeira com valor agregado para minimizar a exploração } \\
\text { florestal. Neste trabalho foram estudados cinco tratamentos com }\end{array} \\
\text { misturas de partículas de madeira de marcenarias e de bagaço de cana-de-açúcar. } \\
\text { Para homogeneização das partículas, foram realizados estudos de composição } \\
\text { granulométrica; em seguida, foram confeccionados três painéis para cada } \\
\text { tratamento com adição de } 10 \% \text { de resina poliuretana derivada de óleo de mamona } \\
\text { e realizaram-se avaliações para determinar as propriedades fisicas e mecânicas } \\
\text { desses painéis. As propriedades físicas e mecânicas obtidas para as misturas com } \\
50 \% \text { de serragem e } 50 \% \text { de bagaço de cana indicaram a possibilidade de produção } \\
\text { dos painéis para uso em ambientes internos em condições secas. }\end{array}$ \\
\hline & $\begin{array}{l}\text { Palavras-chave: Painéis de partículas de madeira. Resíduos de serragem. Bagaço de cana- } \\
\text { de-açúcar. }\end{array}$ \\
\hline & Abstract \\
\hline & $\begin{array}{l}\text { Brazil has seen a growing number of studies on the use of sawdust from industrial } \\
\text { processes for the production of wood panels with added value to minimise forest } \\
\text { exploration. In this article, five treatments with mixtures of wood particles from } \\
\text { carpentry shops and sugarcane bagasse were examined. For particle }\end{array}$ \\
\hline $\begin{array}{r}\text { 1Bruna Bessa Rocha Yano } \\
\text { 1Universidade do Oeste Paulista } \\
\text { Presidente Prudente - SP - Brasil }\end{array}$ & $\begin{array}{l}\text { carpentry shops and sugarcane bagasse were examined. For particle } \\
\text { homogenisation, granulometric composition studies were conducted; } \\
\text { subsequently, three panels were made for each treatment, with the addition of } 10 \% \\
\text { of polyurethane resin from castor oil, and evaluations were performed to }\end{array}$ \\
\hline $\begin{array}{l}\text { 2Sérgio Augusto Mello da Silva } \\
\text { 2Universidade Estadual Paulista } \\
\text { Itha Solteira - SP - Brasil }\end{array}$ & $\begin{array}{l}\text { determine the physical and mechanical properties of the panels. The physical and } \\
\text { mechanical properties obtained with the mixtures with } 50 \% \text { of sawdust and } 50 \% \\
\text { of sugarcane bagasse indicated that the production of panels for indoor use under } \\
\text { dry conditions is possible. }\end{array}$ \\
\hline $\begin{array}{r}\text { Recebido em 23/01/19 } \\
\text { Aceito em 01/04/20 }\end{array}$ & Wood particle panels. Sawdust waste. Sugarcane bagasse. \\
\hline
\end{tabular}




\section{Introdução}

De acordo com a norma brasileira NBR 10004 (ABNT, 2004), os resíduos podem ser definidos como em estado sólido e semissólido, e resultam de atividades de origem industrial, doméstica, hospitalar, comercial, agrícola, de serviços ou de varrição. Quando o resíduo é gerado em diversas áreas de produção, geralmente não é utilizado para outros fins e acaba sendo descartado sem critério, o que causa prejuízos ambientais.

No Brasil, as indústrias de base florestal geram um volume significativo de resíduos durante as fases operacionais, que incluem desde a exploração florestal até o produto final (IWAKIRI et al., 2000).

De acordo com Cerqueira et al. (2012), o volume de perdas e o não aproveitamento dos resíduos florestais na indústria são considerados grandes até mesmo em pequenas marcenarias e serrarias. As indústrias moveleiras tratam os resíduos como lixo resultante do processo de produção e enfrentam problemas com sua destinação (ABREU et al., 2009).

Segundo Albertini, Carmo e Prado Filho (2007), a geração de resíduos florestais no Brasil tem mostrado valores expressivos, considerando sua utilização na cadeia produtiva $-22,5$ milhões de toneladas de madeira serrada. São, portanto, 22,5 milhões de toneladas de resíduos, um problema econômico e ambiental para o país, já que as indústrias ainda não sabem o que fazer com esses subprodutos.

Independentemente do tipo de indústria madeireira, a geração de resíduos é uma consequência direta do processamento primário ou secundário da madeira sólida, de painéis reconstituídos. Para Fontes (1994), de acordo com as características morfológicas, os resíduos industriais são classificados em:

(a) cavacos, partículas com dimensões máximas de $50 \times 20 \mathrm{~mm}$, provenientes de uso de picadores;

(b) maravalhas, resíduos com menos de 2,5 mm;

(c) serragem, partículas de madeira com dimensões entre $0,5 \mathrm{~mm}$ e $2,5 \mathrm{~mm}$ provenientes do uso de serras;

(d) pó, resíduos menores que $0,5 \mathrm{~mm}$; e

(e) lenha, resíduos de maiores dimensões, compostos de costaneiras, aparas e resíduos de topo de tora.

O processamento primário gera a maioria dos resíduos, apesar de algumas variantes determinadas por fatores como tipo de processo, máquinas utilizadas, dimensões e características físicas das toras (CERQUEIRA et al., 2012).

A perda de material na forma de sobras ou resíduos nos cortes de resserra de madeira é em torno de $20 \%$ a $40 \%$, e o aproveitamento de toda a árvore pelas indústrias madeireiras está em torno de $30 \%$ a $60 \%$. O processamento de toras de madeira, além de ser uma variável muito importante para o gerenciamento da produção, é responsável por uma parcela significativa dos impactos ambientais causados pela produção de madeira serrada (NARCISO et al., 2014).

\section{Referencial teórico}

Há vários estudos desenvolvidos para o aproveitamento de subprodutos que objetivam reduzir os impactos ambientais. Pesquisas buscam soluções para essa problemática de dimensões mundiais (MISAGIA et al., 2013).

Segundo Narciso et al. (2014), a identificação dos resíduos provenientes do processamento (desdobro) da madeira é elemento essencial para a análise das possibilidades de aplicação e bom emprego de outros bens.

Uma alternativa mais adequada de aproveitamento de resíduos do processamento de madeiras é a produção de chapas de madeira aglomerada, processo que se caracteriza pela modificação da madeira sólida em partículas pequenas e secas, como aparas e refilos, que podem ser provenientes de serrarias.

Assim como ocorre com os resíduos industriais, a reutilização dos resíduos agrícolas também tem despertado interesse, pois atualmente são materiais abundantes e de baixo custo, mas muitas vezes são removidos dos campos para serem queimados, o que provoca poluição ambiental (ALBERTINI; CARMO; PRADO FILHO, 2007).

Esses resíduos vêm sendo utilizados visando ao aproveitamento dos recursos naturais existentes no Brasil, buscando-se também alternativas que sejam economicamente viáveis para o estudo e aplicação em diversas áreas de pesquisa (TITA; PAIVA; FROLLINI, 2002). 
Segundo Carashi, Leão e Coiado Chamma (2008), os materiais lignocelulósicos provenientes de subprodutos agroindustriais vêm sendo utilizados com sucesso na fabricação de painéis, sendo possível destacar a casca de arroz, folhas de bambu e o bagaço de cana-de-açúcar.

Para Sanchez et al. (2010) e Tita, Paiva e Frollini (2002), o interesse se deve ao fato de que as fibras vegetais são fontes renováveis de matéria-prima, reduzem o impacto ambiental e os custos, possuem baixa densidade e flexibilidade no processamento, e são adaptáveis, não abrasivas, porosas, viscoelásticas, combustíveis, reativas e biodegradáveis.

Há facilidade de cultivo dessa gramínea em praticamente todas as regiões brasileiras, com ciclos de colheita curtos, o que propicia grande volume de matéria-prima para a produção dos painéis (NEGRÃO et al., 2014).

Pedreschi (2009) avaliou a utilização de bagaço de cana-de-açúcar na produção de painéis aglomerados com treze tipos de tratamentos diferentes, tendo em vista o efeito da composição dos painéis em camadas e comparando as propriedades físico-mecânicas de painéis compostos de bagaço e madeira de eucalipto.

Alves e Silva (2014) produziram e avaliaram chapas com resíduos coletados em indústrias madeireiras, com resina bicomponente (derivada de óleo de mamona) e densidade nominal de $0,80 \mathrm{~g} / \mathrm{cm}$, espessura nominal de $10 \mathrm{~mm}, 10 \%$ de resina com base no peso seco, tempo de prensagem de $10 \mathrm{~min}$, temperatura de prensagem de $110{ }^{\circ} \mathrm{C}$ e pressão de prensagem de $5 \mathrm{MPa}$.

O uso da resina poliuretana derivada de mamona teve origem na década de 1940, conforme aponta Vilar (1993 ${ }^{1}$ apud BERTOLINI, 2011). Para Vilar, o óleo da mamona é extraído da semente da planta Ricinus communis, encontrada em regiões tropicais e subtropicais, e abundante no Brasil. Para Dias (2008), com o óleo de mamona, torna-se possível sintetizar polióis e pré-polímeros com características diferenciadas, que, quando misturadas, dão origem à poliuretana.

De acordo com Silva et al. (2013), um aspecto importante a ser considerado é a necessidade de identificação e caracterização de novos ligantes (resinas, adesivos), que proporcionem melhor qualidade aos produtos e minimizem os problemas causados pela emissão de gases tóxicos pelo uso de resinas fenólicas.

Jesus e Calil Junior (2002) estudaram o comportamento do adesivo para o emprego em madeira laminada colada (MLC). O adesivo se mostrou corretamente adequado por possuir grande versatilidade, com propriedades superiores aos polímeros derivados de petróleo, e se tornou uma alternativa tecnicamente viável.

Neste trabalho são confeccionados e avaliados painéis de madeira aglomerada composta de dois subprodutos: o industrial (serragem de madeira proveniente de marcenaria); e o agrícola (bagaço de cana-deaçúcar e resina poliuretana de mamona).

De acordo com Marton (2014), verificou-se que os resíduos de marcenarias industriais apresentam potencialidades para a produção de painéis de madeira aglomerada. A proposta deste trabalho é verificar a melhor composição granulométrica através de peneiramento com diferentes malhas, indicar cinco tratamentos com misturas diferentes de partículas de madeira e de partículas de bagaço de cana-de-açúcar para confecção e avaliação de painéis de resíduos de serragem e de bagaço de cana-de-açúcar, e realizar ensaios para a determinação das propriedades físicas e mecânicas, de acordo com a NBR 14810 (ABNT, 2006).

\section{Método}

A serragem de madeira utilizada neste trabalho é proveniente de marcenarias industriais da região de São José do Rio Preto, SP, e é formada das seguintes espécies de madeiras: Cariniana micrantha (tauari), Goupia glabra (cupiúba), Vochysia guianensis (cambará), Tabebuia alba (ipê) e Apuleialei ocarpa (garapa), com densidades aparentes de $0,68,0,88,0,76,1,02$ e $0,88(\mathrm{~g} / \mathrm{cm})$ respectivamente.

O bagaço de cana utilizado neste trabalho foi coletado em usinas sucroalcoleiras da região de Ilha Solteira, SP, e é proveniente de cana-de-açúcar da espécie Saccharum officinarum.

Para Barros Filho (2009), o valor médio encontrado para a densidade do bagaço de cana de usina é de 0,096 $\mathrm{g} / \mathrm{cm}$.

IVILAR, W.D. Química e tecnologia dos poliuretanos. [S.I.]: Grupo Pronor, 1993. 
A resina utilizada para a confecção dos painéis foi a resina poliuretana bicomponente derivada de óleo de mamona obtida pela Universidade de São Paulo (USP) de São Carlos. De origem vegetal, constitui-se de um isocianato polifuncional denominado pré-polímero (polímero com polimerização incompleta) e de um componente derivado do óleo vegetal de mamona, o poliol, mistura esta que permite sua transformação em diversos produtos, entre eles as resinas à base de poliuretana resistente a solventes e produtos oxidantes com baixa absorção de água (CARDOSO, 2007). A planta Ricinus communis, comumente encontrada em regiões tropicais e subtropicais, abundante no Brasil, produz uma semente da qual se extrai o óleo de rícino.

\section{Cálculo da massa de partículas para a confecção dos painéis}

O cálculo da massa de partículas para a confecção dos painéis foi realizado considerando-se a seguinte Equação 1:

$D=\frac{\mathrm{m}}{\mathrm{v}} \mathrm{g} / \mathrm{cm}^{3}$

Onde:

$\mathrm{D}=$ densidade nominal dos painéis, igual a $0,75 \mathrm{~g} / \mathrm{cm}^{3}$ (ABNT, 2013);

$\mathrm{m}=$ massa em gramas de partículas, a ser determinada para a confecção dos painéis;

$\mathrm{v}=$ volume em centímetros cúbicos dos painéis, definido em função da formadora de colchão com dimensões de 40x40x1 cm.

\section{Seleção granulométrica}

Primeiro foi realizado peneiramento da serragem coletada nas marcenarias, objetivando-se separar os vários tamanhos de partículas; para isso, foram utilizadas peneiras com malhas de 12,5, 9,52, 6,36, 4,36 e 2,36 mm, conforme padronização definida pela NBR 7217 (ABNT, 1987). A Figura 1 ilustra alguns aspectos desse peneiramento.

Figura 1 - Aspectos da retenção de partículas nas peneiras de malha 9,52 mm (a), 4,36 mm (b) e 2,36 $\mathrm{mm}(\mathrm{c})$

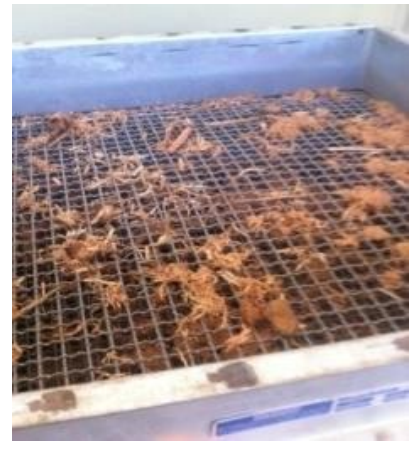

(a)

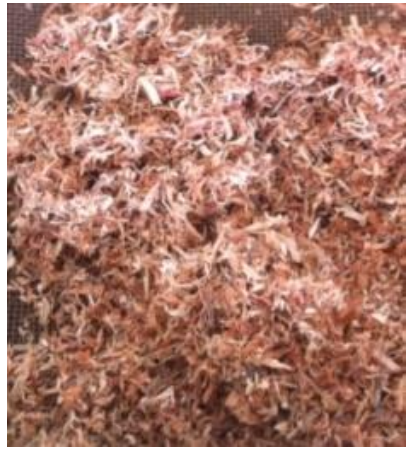

(b)

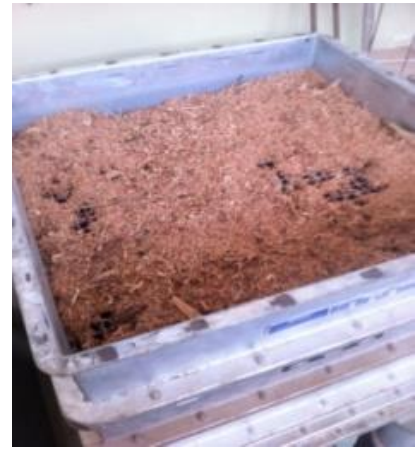

(c)

Figura 2 - Ilustração do bagaço de cana-de-açúcar triturado em moinho de facas
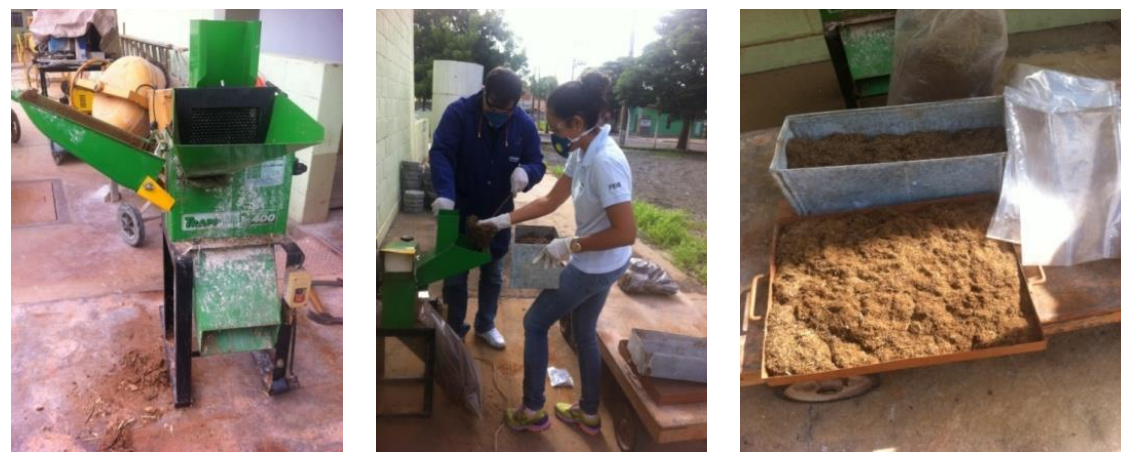

332 Yano, B. B. R.; Silva, S. A. M. da 
A obtenção de partículas na faixa de $4 \mathrm{~mm}$ a $6 \mathrm{~mm}$ de comprimento objetivou melhorar a composição granulométrica das partículas de marcenaria, pois, segundo Marton (2014), esses resíduos apresentam baixas proporções nessa faixa de comprimento.

O bagaço de cana, como mostra a Figura 2, foi triturado e seco em estufa por um período de $72 \mathrm{~h}$, à temperatura de $600 \pm 2{ }^{\circ} \mathrm{C}$, antes de ser misturado com as partículas de marcenaria.

Após a preparação das partículas provenientes da serragem de marcenarias e de bagaço de cana-de-açúcar, foram propostos os tratamentos apresentados na Tabela 1, empregando-se 10\% de adesivo PU-mamona em relação à massa seca de partículas das misturas de cada tratamento para a confecção dos painéis aglomerados nas dimensões de 40x40x1 cm, densidade nominal de $0,80 \mathrm{~g} / \mathrm{cm}^{3}$ e massa seca de $1.280 \mathrm{~g}$. A Tabela 2 apresenta o resumo da composição granulométrica de cada tratamento proposto.

\section{Determinação do teor de umidade dos materiais}

O ensaio para a determinação do teor de umidade tem como objetivo determinar a porcentagem de água presente nas amostras. A umidade corresponde ao peso da água nas amostras e é percebida pela perda de peso quando o bagaço é exposto a uma temperatura em que a água é removida.

Segundo Galvão e Jankowsky (1985), o método de secagem em estufa a $103{ }^{\circ} \mathrm{C}$ é um dos métodos mais precisos de obtenção do teor de umidade da madeira, cujos valores são obtidos com o auxílio de estufas, que permitem regular e manter a temperatura entre $101{ }^{\circ} \mathrm{C}$ e $105^{\circ} \mathrm{C}$, e balança, o que possibilita pesagens com aproximação de $0,1 \mathrm{~g}$.

Tabela 1 - Tratamentos propostos para a confecção dos painéis aglomerados

\begin{tabular}{c|c|c|c|c}
\hline TRATAMENTOS & SERRAGEM (\%) & BAGAÇO (\%) & RESINA (\%) & MASSA TOTAL (g) \\
\hline Referência & 100 & 0 & 10 & 1.280 \\
T1 & 90 & 10 & 10 & 1.280 \\
T2 & 80 & 20 & 10 & 1.280 \\
T3 & 70 & 30 & 10 & 1.280 \\
T4 & 60 & 40 & 10 & 1.280 \\
T5 & 50 & 50 & 10 & 1.280 \\
\hline
\end{tabular}

Tabela 2 - Resumo da composição granulométrica de cada tratamento

\begin{tabular}{|c|c|c|c|c|c|c|}
\hline \multirow{2}{*}{$\begin{array}{c}\text { PENEIRA } \\
(\mathbf{m m})\end{array}$} & $\begin{array}{c}\text { T0 } \\
M a=500,10 \mathrm{~g}\end{array}$ & $\begin{array}{c}\mathrm{T} 1 \\
\mathrm{Ma}=\mathbf{5 0 2 , 1 0 \mathrm { g }}\end{array}$ & $\begin{array}{c}\text { T2 } \\
M a=494 \mathrm{~g}\end{array}$ & $\begin{array}{c}\mathrm{T3} \\
\mathrm{Ma}=\mathbf{5 0 3 , 2 5 \mathrm { g }}\end{array}$ & $\begin{array}{c}\mathrm{T} 4 \\
\mathrm{Ma}=\mathbf{5 0 5 , 2 0 \mathrm { g }}\end{array}$ & 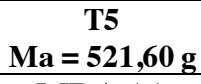 \\
\hline & MRA (g) & MRA (g) & MRA (g) & MRA (g) & MRA (g) & MRA (g) \\
\hline 6,300 & 0,000 & 0,000 & 0,000 & 0,000 & 0,000 & 0,000 \\
\hline 4,760 & 0,500 & 3,750 & 2,450 & 2,650 & 3,400 & 6,950 \\
\hline 2,380 & 349,3 & 304,35 & 301,50 & 224,64 & 196,10 & 167,15 \\
\hline 1,190 & 102,3 & 119,05 & 96,75 & 104,20 & 94,65 & 96,10 \\
\hline 0,595 & 37,50 & 37,50 & 41,15 & 50,45 & 66,70 & 73,60 \\
\hline 0,297 & 7,400 & 22,85 & 37,15 & 54,80 & 70,80 & 94,40 \\
\hline 0,149 & 0,500 & 7,400 & 11,25 & 42,80 & 46,05 & 53,30 \\
\hline 0,075 & 1,900 & 7,200 & 3,750 & 23,70 & 27,50 & 30,10 \\
\hline MF & 4,6 & 4,4 & 4,3 & 3,7 & 3,5 & 3,3 \\
\hline
\end{tabular}

Nota: Legenda:

$M a=$ massa aparente;

MRA = massa retida e acumulada; $\mathrm{e}$

$M F=$ módulo de finura. 
A equação abaixo expressa como é possível obter o valor do teor de umidade de acordo com cada tratamento, conforme a Equação 2:

$U=\frac{\mathrm{MU}-\mathrm{MS}}{\mathrm{MS}} \times 100$

Onde:

$\mathrm{U}=$ teor de umidade residual $(\%)$;

$\mathrm{m}_{\mathrm{u}}=$ massa úmida, expressa em gramas; $\mathrm{e}$

$\mathrm{m}_{\mathrm{s}}=$ massa seca, expressa em gramas.

Foram realizados ensaios para a avaliação da composição granulométrica das misturas de acordo com a NBR 7217 (ABNT, 1987).

A Figura 3 ilustra as misturas de cada tratamento preparadas para receber o adesivo PU-mamona. Em seguida, serão homogeneizadas com o auxílio de misturador de tambor.

Após a adição e a homogeneização do adesivo às partículas, utilizou-se a "formadora de colchão de partículas" para propiciar à mistura de partículas uma forma inicial de 40x40 cm e espessura variável para posterior prensagem com calor. A Figura 4 ilustra as etapas para a preparação do colchão de partículas.

O procedimento para compactação dos painéis foi realizado considerando-se pressão de prensagem de 5 $\mathrm{MPa}$, temperatura de $100{ }^{\circ} \mathrm{C}$ e tempo inicial de $3 \mathrm{~min}$; alívio de pressão por $30 \mathrm{~s}$ para eliminar gases e evitar a formação de bolhas nos painéis; e 7 min finais de pressão de prensagem.

A Figura 5 ilustra a prensa com controle de temperatura e pressão, com aplicação de $80 \mathrm{t}$ de carga, utilizada na confecção dos painéis e um conjunto de painéis após serem prensados, constituídos com partículas de madeira provenientes de resíduos de marcenaria e com partículas provenientes de bagaço de cana-de-açúcar.

\section{Figura 3 - Partículas preparadas para a adição do adesivo PU-mamona}

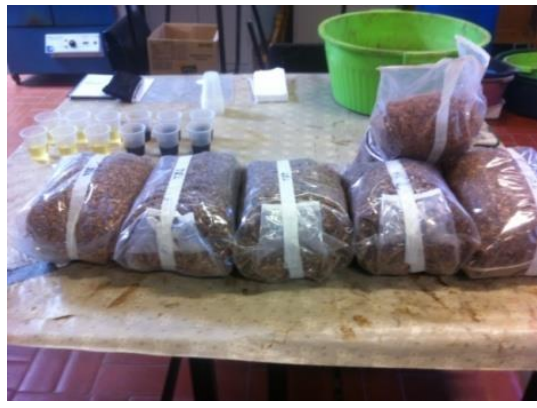

(a) Misturas preparadas

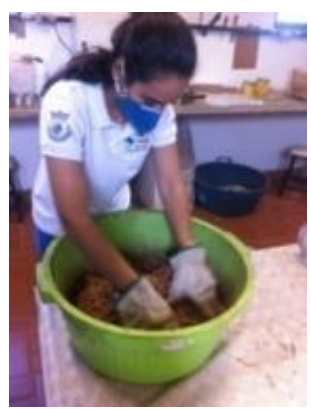

(b) Adição do adesivo

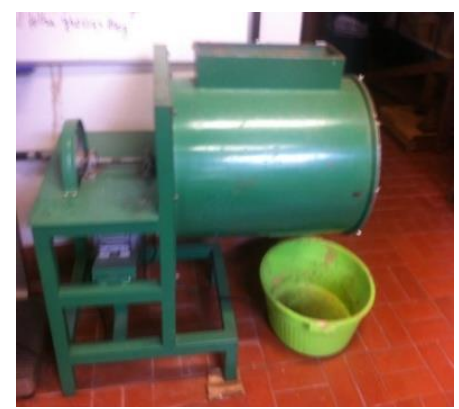

(c) Misturador de adesivo

Figura 4 - Preparação do colchão de partículas
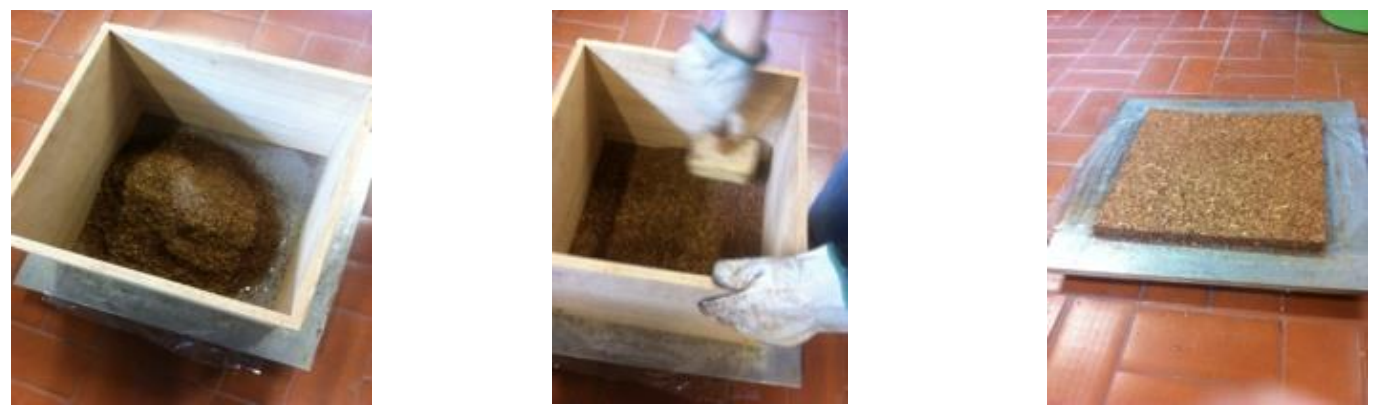
Figura 5 - Prensa com controle de temperatura e conjunto de painéis após prensagem
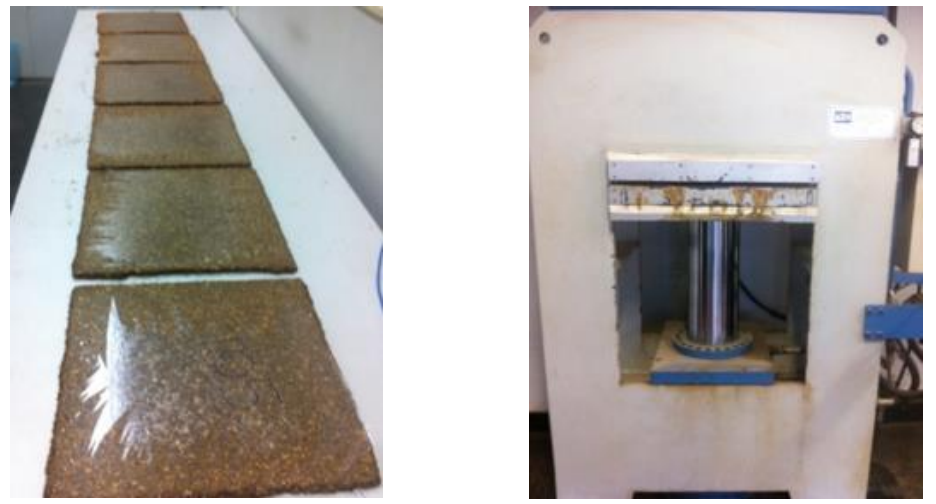

\section{Determinação do inchamento de 24 horas}

A determinação do inchamento de 24 horas foi realizada em corpos de prova de $25 \times 25 \times 10 \mathrm{~mm}$, empregando-se a Equação 3:

$\mathrm{I}=\frac{\mathrm{e} 1-\mathrm{e} 0}{\mathrm{e} 0} \times 100$

Onde:

$\mathrm{I}=$ inchamento em espessura do corpo de prova, em porcentagem;

$\mathrm{e}_{1}=$ espessura do corpo de prova após o período de imersão considerado, em milímetros; e

$\mathrm{e}_{0}=$ espessura do corpo de prova antes da imersão, em milímetros.

\section{Determinação do teor de umidade dos painéis}

A determinação do teor de umidade dos painéis foi realizada em corpos de prova de $50 \times 50 \times 10 \mathrm{~mm}$, empregando-se a Equação 4:

$U=\frac{m u-m s}{m s} \times 100$

Eq. 4

Onde:

$\mathrm{U}=$ umidade residual do corpo de prova, em porcentagem;

$\mathrm{m}_{\mathrm{u}}=$ massa úmida do corpo de prova, em gramas; e

$\mathrm{m}_{\mathrm{s}}=$ massa seca do corpo de prova, em gramas.

\section{Determinação da densidade aparente dos painéis}

A determinação da densidade aparente dos painéis foi realizada em corpos de prova de $50 \times 50 \times 10 \mathrm{~mm}$, empregando-se a Equação 5:

Dap $=\frac{\mathrm{mcp}}{\mathrm{vcp}} \mathrm{g} / \mathrm{cm}^{3}$

Onde:

Dap $=$ densidade aparente dos painéis, igual a $0,75 \mathrm{~g} / \mathrm{cm}^{3}$;

mcp = massa em gramas do corpo de prova; e

$\mathrm{vch}=$ volume em centímetros cúbicos do corpo de prova.

\section{Determinação da resistência à flexão dos painéis}

Para o cálculo da resistência à flexão do corpo de prova, utilizou-se a Equação 6 :

$M O R=\frac{1,5 \times(P \times D)}{B \times(E)^{2}}$ 
Onde:

MOR = módulo de ruptura, em Megapascals;

$\mathrm{P}=$ carga de ruptura lida no indicador de carga, em Newtons;

$\mathrm{D}=$ distância entre apoios do aparelho, em milímetros;

$\mathrm{B}=$ largura do corpo de prova, em milímetros; e

$\mathrm{E}=$ espessura média tomada em três pontos do corpo de prova, em milímetros.

\section{Determinação do módulo de elasticidade dos painéis}

Para determinação do módulo de elasticidade foi utilizada a seguinte Equação 7:

$M O E=\frac{P 1 \times D^{3}}{d \times 4 \times B \times E^{3}}$

Onde:

MOE = módulo de elasticidade, em Megapascals;

P1 = carga no limite proporcional lida no indicador de cargas, em Newtons;

$\mathrm{D}=$ distância entre os apoios do aparelho, em milímetros;

$\mathrm{d}$ = deflexão, em milímetros, correspondente à carga $\mathrm{P} 1$;

$\mathrm{B}=$ largura do corpo de prova, em milímetros; e

$\mathrm{E}=$ espessura média tomada em três pontos do corpo de prova, em milímetros.

\section{Determinação da tração perpendicular dos painéis}

Para os ensaios de tração perpendicular, foram preparados corpos de prova nas dimensões 50x50 mm.

$T P=\frac{P}{S}$

Onde:

$\mathrm{TP}=$ resistência à tração perpendicular, em Megapascals;

$\mathrm{P}=$ carga na ruptura, em Newtons; $\mathrm{e}$

$\mathrm{S}=$ área da superfície do corpo de prova, em milímetros quadrados.

\section{Resultados e discussões}

A adição de partículas de bagaço de cana-de-açúcar às partículas provenientes de resíduos de marcenaria possibilitou melhorar a distribuição granulométrica dos tratamentos, como mostra a Figura 6. O módulo de finura das partículas foi diminuindo à medida que se aumentava a massa de partículas de bagaço de cana-deaçúcar, indicando que a adição dessas partículas propiciou maior distribuição na faixa de $4 \mathrm{~mm}$ a $6 \mathrm{~mm}$.

Inicialmente foram avaliados os teores de umidade das misturas de cada tratamento. A Tabela 3 apresenta os valores determinados. Ressalta-se que, antes de misturar as partículas de resíduo de marcenaria com as partículas de bagaço de cana-de-açúcar, seus teores de umidade correspondiam a 11,32\% e 8,5\% respectivamente.

A Tabela 3 indica que T0 é o tratamento com o maior porcentual por ser composto somente de madeira. À medida que o bagaço vai sendo incorporado nas respectivas quantidades, o teor de umidade diminui.

A Tabela 4 apresenta os valores mínimos das propriedades dos painéis propostos pela norma brasileira e os valores determinados com a realização dos ensaios.

$\mathrm{Na}$ Tabela 4, para os painéis do T0, que não possuem adição de partículas de bagaço de cana-de-açúcar, e para os painéis do T5, com $50 \%$ de adição de bagaço de cana-de-açúcar, observam-se densidades dentro do intervalo definido pela norma NBR 14810 (ABNT, 2006) para painéis de média densidade $(0,55 \mathrm{~g} / \mathrm{cm}$ a $0,75 \mathrm{~g} / \mathrm{cm})$, enquanto os painéis dos demais tratamentos apresentaram densidade acima daquela do intervalo. 
Figura 6 - Curva da composição granulométrica dos tratamentos das misturas de T0 a T5

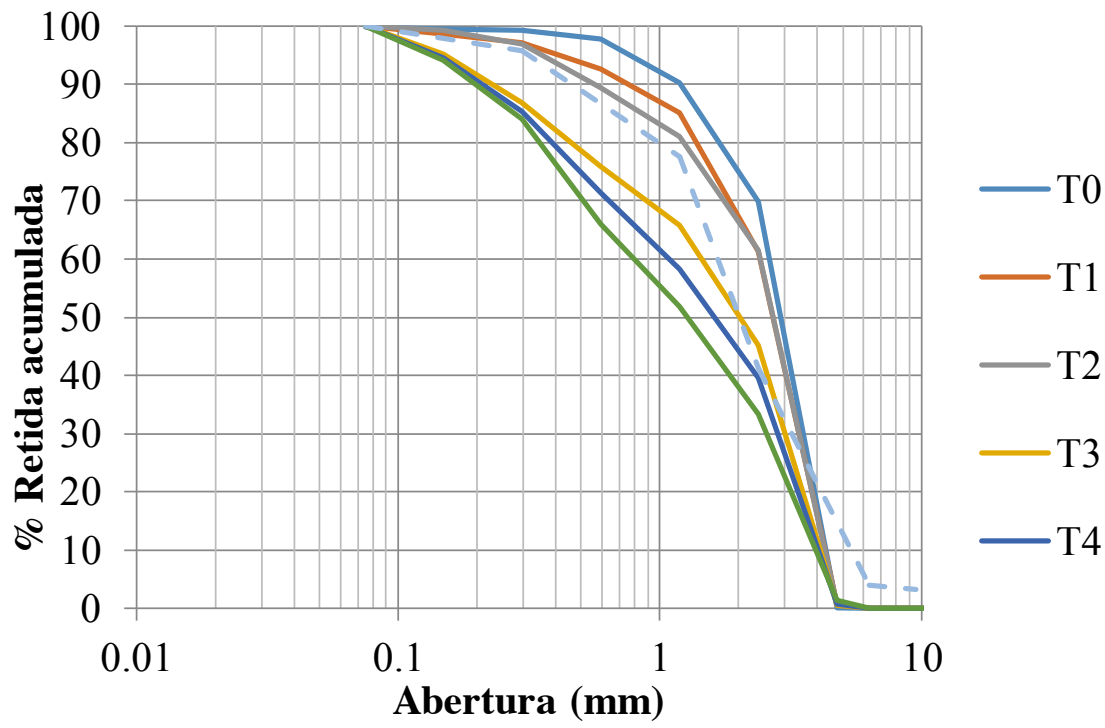

Tabela 3 - Teores de umidades das misturas de cada tratamento proposto

\begin{tabular}{c|c|c|c}
\hline TRATAMENTOS & $\begin{array}{c}\text { PARTÍCULAS DE } \\
\text { SERRAGEM (g) } \\
\overline{\boldsymbol{u}}=\mathbf{1 1 , 3 2 \%}\end{array}$ & $\begin{array}{c}\text { PARTÍCULAS DE } \\
\text { BAGAÇO (g) } \\
\overline{\boldsymbol{u}}=\mathbf{8 , 5 \%}\end{array}$ & $\begin{array}{c}\text { UMIDADE } \\
\mathbf{( \% )}\end{array}$ \\
\hline T0 & 1.280 & 0 & 11,32 \\
T1 & 1.152 & 128 & 8,66 \\
T2 & 1.024 & 256 & 7,85 \\
T3 & 896 & 384 & 6,89 \\
T4 & 768 & 512 & 6,38 \\
T5 & 640 & 640 & 6,56 \\
\hline
\end{tabular}

Tabela 4 - Densidade dos painéis de cada tratamento proposto

\begin{tabular}{c|c}
\hline Tratamento & Densidade média $\left(\mathbf{g} / \mathbf{c m}^{3}\right)$ \\
\hline T0 - 100\% SM e 0\% BC & $0,73 \ldots \mathrm{a}$ \\
$\mathrm{T} 1-90 \% \mathrm{SM}$ e $10 \% \mathrm{BC}$ & $0,89 \mathrm{~b}$ \\
$\mathrm{~T} 2-80 \% \mathrm{SM}$ e $20 \% \mathrm{BC}$ & $0,83 \mathrm{~b}$ \\
$\mathrm{~T} 3-70 \% \mathrm{SM}$ e $30 \% \mathrm{BC}$ & $0,77 \mathrm{~b}$ \\
$\mathrm{~T} 4-60 \% \mathrm{SM}$ e $40 \% \mathrm{BC}$ & $0,79 \mathrm{~b}$ \\
$\mathrm{~T} 5-50 \% \mathrm{SM}$ e $50 \% \mathrm{BC}$ & $0,73 \ldots \mathrm{a}$ \\
\hline
\end{tabular}

De acordo com os parâmetros para produção dos painéis, foi proposta densidade nominal de $0,80 \mathrm{~g} / \mathrm{cm}^{3}$. Esse parâmetro foi considerado supondo-se que o bagaço de cana-de-açúcar poderia influenciar negativamente a densidade do painel e consequentemente não atingisse os requisitos estabelecidos pela NBR 14810 (ABNT, 2006). Entretanto, verifica-se na Tabela 4 que as misturas com o bagaço de cana-de-açúcar para os tratamentos T1 e T2 propiciaram densidades médias para os painéis acima da densidade nominal prevista. Para as misturas dos tratamentos T3 e T4, ou seja, com teores de bagaço de cana-de-açúcar com $30 \%$ e $40 \%$, verificou-se que as densidades médias dos painéis ficaram acima da densidade nominal proposta e muito acima do intervalo proposto pela NBR, o que nos possibilita inferir que os teores de $30 \%$ e $40 \%$ de bagaço de cana-de-açúcar contribuíram para aumentar a densidade dos painéis.

Com relação aos painéis dos tratamentos T0 e T5, correspondentes aos painéis de referência e com $50 \%$ de bagaço de cana-de-açúcar e 50\% de madeira, verificou-se que as densidades médias foram determinadas dentro do intervalo previsto pela NBR. Consequentemente é possível inferir que o bagaço de cana-de-açúcar não interfere negativamente na densidade dos painéis. 
As análises estatísticas apontam que os tratamentos T0 e T5 diferem significativamente dos tratamentos T1, T2, T3 e T4. Observa-se também que os valores médios de densidade dos painéis são superiores aos valores estabelecidos pela NBR com intervalo de $0,55 \mathrm{~g} / \mathrm{cm}$ a $0,75 \mathrm{~g} / \mathrm{cm}$. Essa diferença pode ser atribuída ao comportamento da fibra do bagaço de cana quando comprimido, pois, devido ao fato de o bagaço de canade-açúcar ser menos denso que as partículas de madeira, é possível inferir que as misturas absorveram com mais eficiência o adesivo poliuretano bem como facilitaram a compactação das misturas, o que possibilitou maior acomodação entre as partículas.

Nos estudos de Soares et al. (2017), houve acréscimo da razão de compactação com o aumento da inserção de bagaço de cana-de-açúcar no painel.

A Tabela 5 apresenta os valores médios de inchamento dos painéis após $24 \mathrm{~h}$ de imersão em água.

De acordo com a Tabela 5, ao se analisar o inchamento em espessura dos painéis do T0, ou seja, sem adição de partículas de bagaço de cana-de-açúcar, verifica-se o valor de $24,27 \%$, isto é, acima do valor de referência da norma NBR 14810 (ABNT, 2006) para painéis de média densidade com valor de até 18\%. Entretanto, observando-se os demais tratamentos com adição de bagaço de cana, somente o teor de umidade para os painéis do T2 ficou ligeiramente acima do recomendado pela norma citada. Para os demais painéis, todos os valores estão de acordo com a NBR.

Iwakiri et al. (2000), estudando a produção de painéis aglomerados com a utilização de resíduos de serraria, obtiveram valores médios de inchamento em espessura para 24 h de imersão em água de 23,51\% a 38,81\%, valores aproximados aos encontrados neste trabalho.

Para Mendes et al. (2010), as propriedades físicas de aglomerados de bagaço de cana com madeira de eucalipto nos estudos apresentaram valores médios de inchamento em espessura para $2 \mathrm{~h}$ e $24 \mathrm{~h}$ de imersão em água de $9,15 \%$ e $18,16 \%$ respectivamente. Esses valores também são bem próximos aos encontrados neste trabalho.

Os resultados de inchamento obtidos para os painéis com misturas de madeira e bagaço de cana-de-açúcar podem estar relacionados à melhor compactação das misturas devido à presença do bagaço de cana, que provavelmente, por causa de sua baixa densidade, propiciou melhor compactação aos painéis, maior absorção do adesivo e, consequentemente, maior aproximação entre as partículas, diminuindo os espaços vazios e melhorando a resistência ao inchamento.

A Tabela 6 apresenta uma análise comparativa das perdas entre os teores de umidade das misturas de partículas de cada tratamento com o teor de umidade dos painéis.

Comparando-se o teor de umidade das partículas dos tratamentos T1 a T5 com o teor de umidade dos painéis, observam-se perdas de aproximadamente $0,8 \%$, que são decorrentes do processo de confecção com temperatura de $1.000{ }^{\circ} \mathrm{C}$. Na Tabela 5 , verifica-se que foram determinados teores de umidade para os painéis na ordem de $6 \%$, ou seja, dentro do recomendado pela norma brasileira.

A Tabela 7 mostra os valores das propriedades mecânicas determinados para os painéis de cada tratamento, sendo eles módulo de ruptura e elasticidade na flexão estática.

O ensaio de flexão estática, como mostra a Figura 7, foi realizado em corpos de prova nas dimensões (20 vezes a espessura $+50 \mathrm{~mm}$ ) x $50 \mathrm{~mm}$, de acordo com a NBR 14810 (ABNT, 2006).

Neste ensaio foram determinados o módulo de elasticidade (MOE) e o módulo de ruptura (MOR). Para os ensaios de tração perpendicular (TP) descrito na Equação 8, foram preparados corpos de prova nas

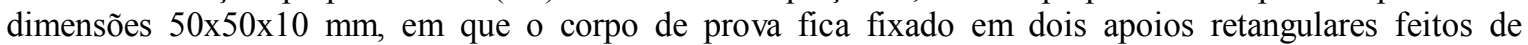
madeira serrada. O corpo de prova é comprimido em um sargento (grampo) durante $24 \mathrm{~h}$, ilustrado na Figura 8.

Após a colagem, o corpo de prova é fixado na máquina universal de ensaios para que este seja rompido à tração perpendicular (Figura 9).

De acordo com a NBR14810-2 (ABNT, 2013), o valor apresentado na Tabela 6 para o MOR dos painéis do T0, T1, T2 e T4 está abaixo dos valores recomendados pela norma citada; entretanto, os valores encontrados para os painéis do T3 e T5 estão em conformidade com a norma.

De acordo com a Figura 3, os painéis do T5 apresentaram aproximadamente $10 \%$ da massa de suas partículas na faixa de $4 \mathrm{~mm}$ a $6 \mathrm{~mm}$ de comprimento. 
Tabela 5 - Resultados dos ensaios para caracterização das propriedades físicas

\begin{tabular}{c|c}
\hline Tratamento & Inchamento de 24 horas (\%) \\
\hline T0-100\% SM e 0\% BC & $24,27 \ldots \mathrm{ab}$ \\
$\mathrm{T} 1-90 \% \mathrm{SM}$ e $10 \% \mathrm{BC}$ & $17,06 \ldots \mathrm{b}$ \\
$\mathrm{T} 2-80 \% \mathrm{SM}$ e $20 \% \mathrm{BC}$ & $18,46 \ldots \mathrm{b}$ \\
$\mathrm{T} 3-70 \% \mathrm{SM}$ e $30 \% \mathrm{BC}$ & $15,53 \ldots \mathrm{a}$ \\
$\mathrm{T} 4-60 \% \mathrm{SM}$ e $40 \% \mathrm{BC}$ & $17,93 \ldots \mathrm{b}$ \\
$\mathrm{T} 5-50 \% \mathrm{SM}$ e $50 \% \mathrm{BC}$ & $15,10 \ldots \mathrm{a}$ \\
\hline
\end{tabular}

Tabela 6 - Avaliação da umidade dos painéis

\begin{tabular}{c|c|c|c}
\hline Tratamentos & $\begin{array}{c}\text { Umidade média } \\
\text { das partículas (\%) }\end{array}$ & $\begin{array}{c}\text { Umidade média } \\
\text { dos painéis (\%) }\end{array}$ & $\begin{array}{c}\text { Perda da umidade } \\
\text { dos painéis }(\boldsymbol{\%})\end{array}$ \\
\hline T0 - 100\% SM e 0\% BC & 11,32 & 6,70 & 0,591 \\
T1 - 90\% SM e 10\% BC & 8,66 & 6,88 & 0,794 \\
T2 - 80\% SM e 20\% BC & 7,85 & 6,48 & 0,825 \\
T3 - 70\% SM e 30\% BC & 6,89 & 6,09 & 0,883 \\
T4 - 60\% SM e 40\% BC & 6,38 & 5,80 & 0,909 \\
T5 - 50\% SM e 50\% BC & 6,56 & 5,70 & 0,869 \\
\hline
\end{tabular}

Figura 7 - Corpo de prova de flexão durante a execução do ensaio

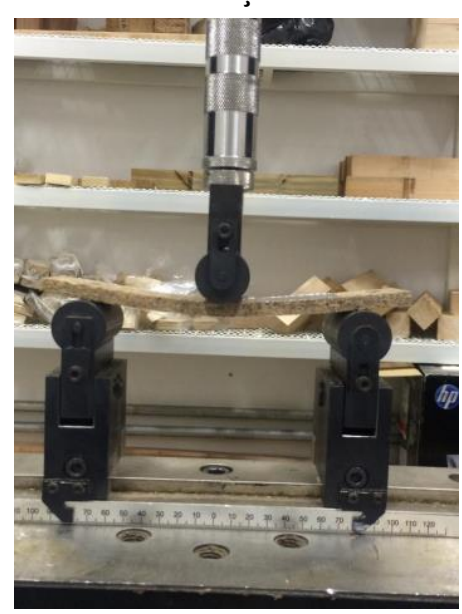

Figura 8 - Grampo utilizado na fixação do corpo de prova ao apoio em madeira serrada

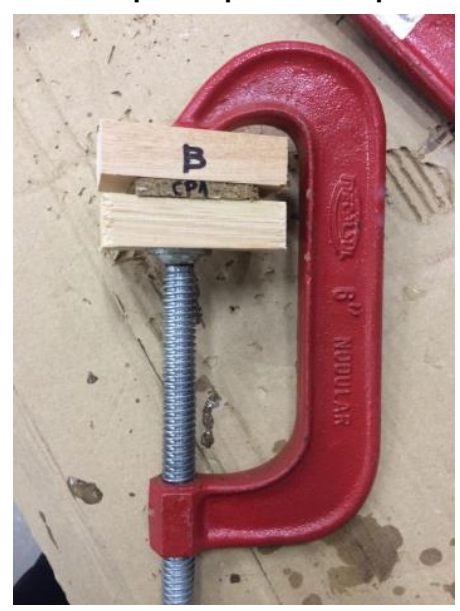


Tabela 7 - Valores das propriedades mecânicas dos painéis

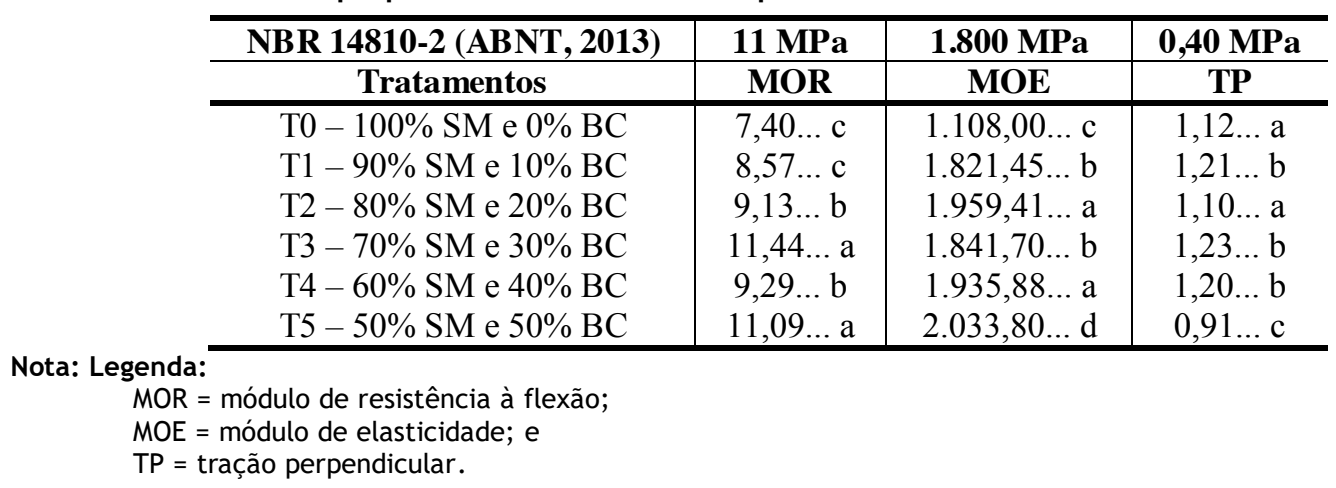

Figura 9 - Corpo de prova já rompido durante o ensaio de tração perpendicular

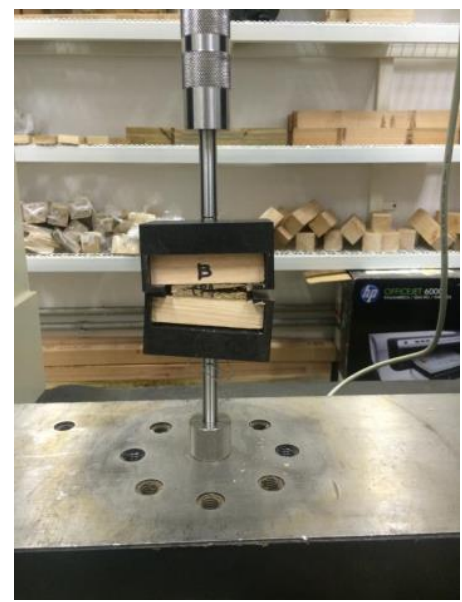

Vale ressaltar que, apesar de a adição de partículas de bagaço de cana-de-açúcar ter melhorado de modo geral as propriedades físicas e mecânicas dos painéis, esse percentual, nessa faixa de comprimento das partículas, ainda é baixo, ou seja, considerando-se os resultados de ensaios obtidos para os painéis desse tratamento, verificou-se que há necessidade de se aumentar a massa de partículas na faixa de $4 \mathrm{~mm}$ a $6 \mathrm{~mm}$.

Com relação ao MOE, verifica-se na Tabela 6 que os painéis dos T1, T2, T3, T4 e T5 atingiram a resistência adequada segundo o documento normativo, pois, independentemente da quantidade de partículas de bagaço de cana-de-açúcar em cada tratamento, é possível inferir que seus comprimentos na faixa de $4 \mathrm{~mm}$ a $6 \mathrm{~mm}$ influenciaram o MOE dos painéis.

$\mathrm{Na}$ Tabela 7, verifica-se que os valores de TP dos painéis de todos os tratamentos são superiores a $0,40 \mathrm{MPa}$, ou seja, acima dos valores exigidos pela norma. Consequentemente, é possível inferir que tanto o adesivo PU-mamona como a adição de partículas de bagaço de cana-de-açúcar foram eficientes e propiciaram boas resistências à tração perpendicular.

Considerando-se que o melhor resultado para as propriedades dos painéis foi para o T5, realizou-se um novo estudo, mais detalhado, com a confecção de cinco painéis do T5 e partículas na faixa de granulometria de 6 mm. A Tabela 8 apresenta os valores obtidos para as propriedades físicas desses painéis.

Conforme se observa na Tabela 8 , em função dos ajustes na composição granulométrica das partículas, o teor de umidade e o inchamento estão de acordo com as exigências da norma, e a densidade foi determinada com valores superiores à referência normativa mínima. A Tabela 9 apresenta os valores das propriedades mecânicas obtidas.

Na Tabela 9 verifica-se a análise comparativa entre os valores normativos mínimos e os valores determinados para MOR, MOE e TP obtidos com os ensaios para caracterização dos painéis. Considerandose os resultados, é possível inferir que os ajustes propostos para o T5 propiciaram melhor resistência mecânica aos painéis. 
A Tabela 10 apresenta uma análise descritiva da absorção, do inchamento, da densidade e da umidade dos painéis confeccionados com o T5 ajustado.

De acordo com as análises apresentadas na Tabela 10, é possível afirmar que os resultados obtidos para as propriedades físicas dos painéis são homogêneos, pois se verifica que os coeficientes de variação são inferiores a 30\%; consequentemente, ocorre pouca dispersão de valores em torno das médias avaliadas. Nesse caso, os valores médios avaliados representam significativamente todos os valores obtidos com os ensaios para caracterização das propriedades físicas avaliadas dos painéis.

A Tabela 11 apresenta uma análise descritiva do MOR, do MOE e TP dos painéis confeccionados com o T5 ajustado.

As análises apresentadas na Tabela 11 permitem afirmar que os resultados obtidos para as propriedades mecânicas dos painéis são homogêneos, pois se verifica que os coeficientes de variação são inferiores a $30 \%$; consequentemente, ocorre pouca dispersão de valores em torno das médias avaliadas.

Tabela 8 - Valores das propriedades físicas

\begin{tabular}{c|c|c|c}
\hline NBR14810-2 $($ ABNT, 2013) & 0,55 a $0,75\left(\mathrm{~g} / \mathrm{cm}^{3}\right)$ & 5 a $13(\%)$ & $18(\%)$ \\
\hline TRATAMENTOS & DENSIDADE & TEOR UMIDADE & INCHAMENTO 24H \\
\hline T5 & 0,94 & 9,75 & 11,34 \\
\hline
\end{tabular}

Tabela 9 - Valores das propriedades mecânicas dos painéis

\begin{tabular}{c|c|c|c}
\hline NBR14810-2 (ABNT, 2014) & $11 \mathrm{MPa}$ & $1.800 \mathrm{MPa}$ & $0,40 \mathrm{MPa}$ \\
\hline TRATAMENTO & MOR & MOE & TP \\
\hline T5 & 18,63 & 2186,18 & 0,74 \\
\hline
\end{tabular}

Nota: Legenda:

MOR = módulo de resistência à flexão;

$\mathrm{MOE}$ = módulo de elasticidade; $\mathrm{e}$

TP = tração perpendicular.

Tabela 10 - Análise descritiva das propriedades físicas dos painéis

\begin{tabular}{|c|c|c|c|c|c|c|}
\hline \multirow[b]{2}{*}{$\begin{array}{l}\text { Propriedades } \\
\text { físicas }\end{array}$} & \multicolumn{6}{|c|}{ Estatísticas } \\
\hline & Mínimo & Máximo & Média & $\begin{array}{l}\text { Desvio } \\
\text { padrão }\end{array}$ & $\begin{array}{c}\text { Coeficiente de } \\
\text { variação }(\%)\end{array}$ & $\begin{array}{l}\text { Intervalo de } \\
\text { confiança da } \\
\text { média }(95 \%)\end{array}$ \\
\hline Absorção (\%) & 10,80 & 34,49 & 23,16 & 6,10 & 26,33 & {$[20,39 ; 25,94]$} \\
\hline Inchamento $(\%)$ & 11,31 & 30,20 & 19,95 & 4,48 & 22,94 & {$[17,50 ; 21,58]$} \\
\hline Densidade $\left(\mathrm{kg} / \mathrm{m}^{3}\right)$ & 787,10 & $1.050,00$ & 944,20 & 80,06 & 8,48 & {$[913,16 ; 975,25]$} \\
\hline Umidade $(\%)$ & 7,10 & 10,02 & 8,42 & 0,49 & 5,79 & {$[8,23 ; 8,61]$} \\
\hline
\end{tabular}

Tabela 11 - Análise descritiva das propriedades mecânicas dos painéis

\begin{tabular}{c|c|c|c|c|c|c}
\hline \multirow{2}{*}{$\begin{array}{c}\text { Propriedade } \\
\text { smecânicas }\end{array}$} & Mínimo & Máximo & Média & $\begin{array}{c}\text { Desvio } \\
\text { padrão }\end{array}$ & $\begin{array}{c}\text { Coeficiente de } \\
\text { variação (\%) }\end{array}$ & $\begin{array}{c}\text { Intervalo de } \\
\text { confiança da } \\
\text { média (95\%) }\end{array}$ \\
\hline MOR $(\mathrm{MPa})$ & 18,56 & 18,70 & 18,63 & 0,04 & 0,24 & {$[18,60 ; 18,65]$} \\
MOE $(\mathrm{MPa})$ & 1.214 & 3.271 & 2.330 & 632,31 & 27,14 & {$[1.964,66 ; 2.694,83]$} \\
TP $(\mathrm{MPa})$ & 0,50 & 0,96 & 0,74 & 0,14 & 18,97 & {$[0,64 ; 0,84]$} \\
\hline
\end{tabular}

Entre as propriedades que caracterizam a qualidade dos painéis, a resistência à tração perpendicular, como mostra a Figura 10, e a densidade são muito importantes porque também estão diretamente relacionadas com a eficiência da resina empregada para aglutinar as partículas.

Estatisticamente, espera-se uma correlação positiva entre tais propriedades. A Figura 11, a seguir, ilustra o comportamento das propriedades conjuntamente. 
Uma análise gráfica para verificar a hipótese de independência dos resíduos pode ser feita por meio do gráfico dos resíduos versus a ordem. Analisando o gráfico da Figura 12, observa-se que os pontos não parecem ter uma tendência; por isso, há indícios de independência dos erros.

Pelo teste de Kolmogorov-Smirnov com P-valor de 0,9689, pode-se confirmar a normalidade dos resíduos. Esses resultados podem ser verificados no gráfico Normal Q-Q plot, ilustrado na Figura 13.

De acordo com o gráfico, os resultados dos tratamentos apresentam diferenças significativas entre si.

Em relação à propriedade de módulo de ruptura à flexão, apresentou valor mínimo de $18,56 \mathrm{MPa}$, com variação em torno da média de $0,24 \%$, valor acima da norma para painéis não estruturais (11 MPa) e para painéis estruturais $(16 \mathrm{MPa})$. Em relação ao módulo de elasticidade, os resultados no intervalo de $95 \%$ de confiança encontram-se dentro do valor mínimo proposto pela norma NBR 14810-2 (ABNT, 2013) para painéis estruturais de $6 \mathrm{~mm}$ em condições secas (1800 MPa). Os resultados obtidos no ensaio de tração perpendicular têm valor mínimo de $0,50 \mathrm{MPa}$, estando acima do valor mínimo da norma NBR 14810-2 (ABNT, 2013) para painéis de uso estrutural $(0,40 \mathrm{MPa})$.

Sugere-se a realização de ajustes na granulometria dessas partículas para a faixa de $4 \mathrm{~mm}$ a $6 \mathrm{~mm}$ de comprimento e aumento do teor de resina PU-mamona par 12\%. Essa sugestão objetiva produzir painéis que se classifiquem segundo a NBR 14810-2 (ABNT, 2013) como "Painéis não Estruturais para Uso em Condições Úmidas - Tipo 3" e "Painéis Estruturais para Uso em Condições Úmidas - Tipo 5".

Figura 10 - Valores obtidos com os ensaios para resistência à tração perpendicular

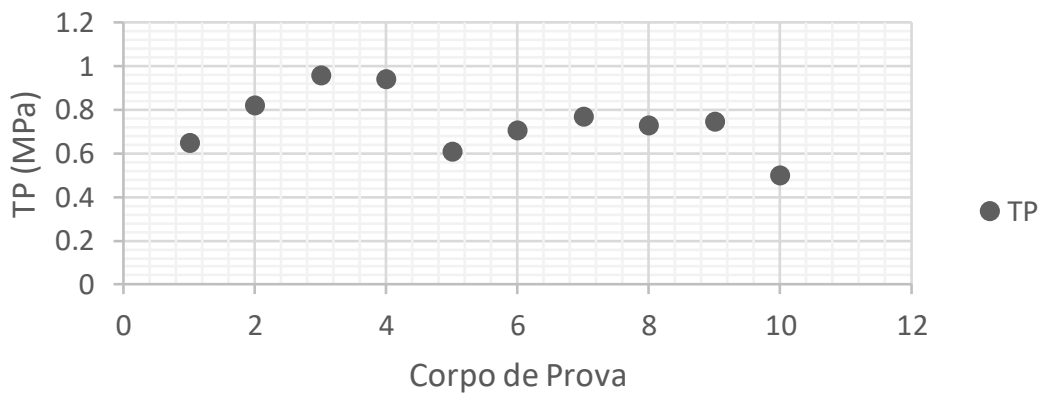

Figura11 - Análise da regressão linear entre os valores obtidos para tração perpendicular e densidade Reta de Regressão

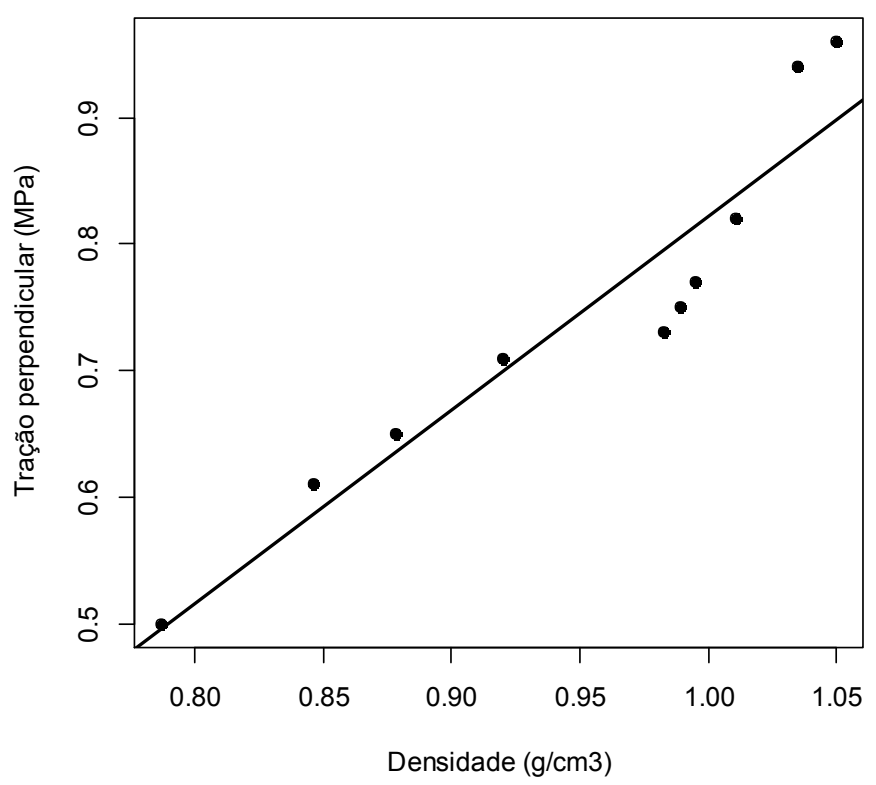


Figura 12 - Gráfico para análise da tendência dos resíduos

\section{Resíduos x Ordem}

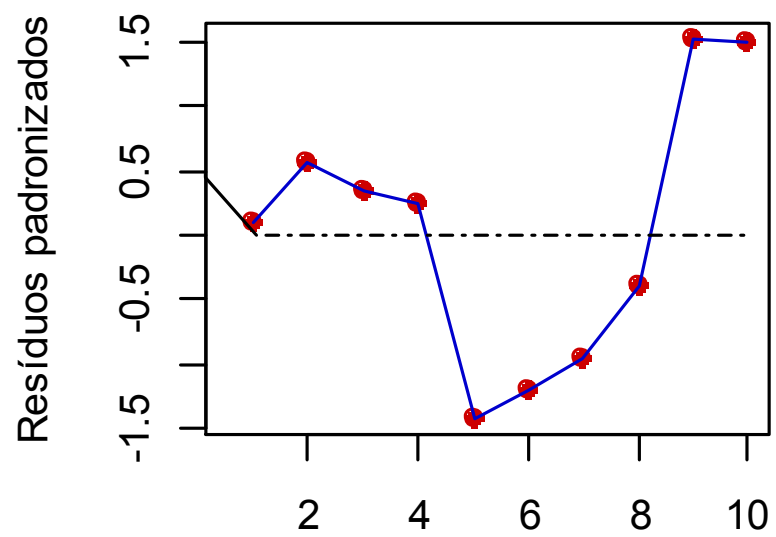

Ordem

Figura 13 - Gráfico para verificação da normalidade dos resíduos

\section{Normal Q-Q plot dos Resíduos}

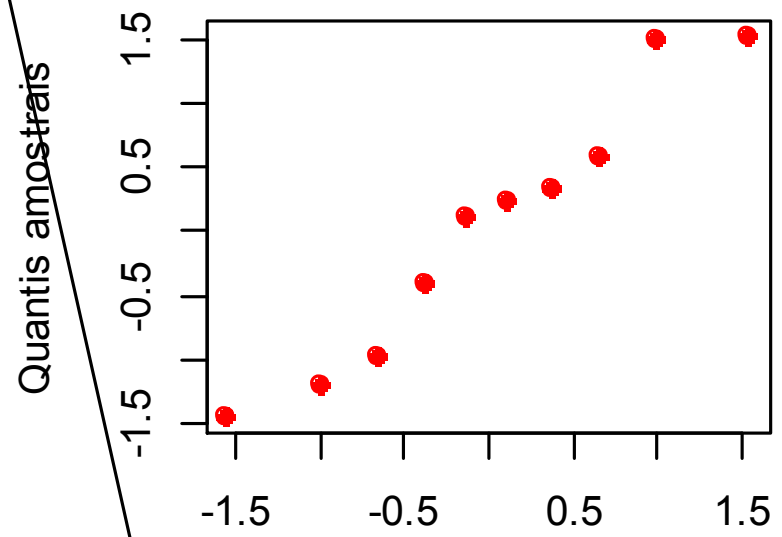

Quantis teóricos

\section{Conclusão}

A utilização de partículas de bagaço de cana-de-açúcar adicionadas a misturas de partículas de madeira provenientes de resíduo de marcenarias com o objetivo de ajustar a composição granulométrica da mistura propiciou aos tratamentos melhores distribuições granulométricas na faixa de $4 \mathrm{~mm}$ a $6 \mathrm{~mm}$.

A densidade dos painéis possivelmente foi influenciada pela densidade do bagaço de cana, fato observado pela maior densidade obtida dos painéis em relação à maior quantidade de bagaço de cana utilizada sem tratamento específico, sem gastar muita energia, de modo a contribuir com o meio ambiente.

As propriedades mecânicas dos painéis foram bastante satisfatórias, principalmente para painéis do grupo T5, com 50\% de serragem de madeira e 50\% de bagaço de cana. Apresentaram-se superiores aos painéis comerciais e produtos análogos encontrados na literatura.

A propriedade de módulo de ruptura à flexão apresentou valor mínimo de 18,56 MPa, com variação em torno da média de $0,24 \%$, acima da norma para painéis não estruturais $(11 \mathrm{MPa})$ e para painéis estruturais (16 MPa). Em relação ao módulo de elasticidade, os resultados no intervalo de $95 \%$ de confiança encontram- 
se dentro do valor mínimo proposto pela norma NBR 14810-2 (ABNT, 2013) para painéis estruturais de 6 mm em condições secas (1.800 MPa). Os resultados obtidos no ensaio de tração perpendicular têm valor mínimo de 0,50 MPa, estando acima do valor mínimo da norma NBR 14810-2 (ABNT, 2013) para painéis de uso estrutural $(0,40 \mathrm{MPa})$.

Em relação às propriedades de inchamento e absorção, os painéis do grupo T5 apresentaram desempenho superior ao de produtos comerciais análogos. Essas propriedades podem ter sido influenciadas pela adição do bagaço de cana e pela interação do adesivo com o bagaço. Essa melhor interação aumentou a densidade e reduziu os vazios, melhorando a capacidade de resistir à água.

Os painéis com bagaço de cana atenderam às exigências da norma quanto às propriedades físicas de umidade e inchamento, todavia não apresentaram resultados mecânicos satisfatórios nos tratamentos T1, T2 e T4, enquanto o T5, com mistura de 50\% de madeira e 50\% de bagaço, mostrou os melhores resultados.

A utilização de resíduos de madeira e bagaço de cana pode ser uma alternativa interessante na confecção de compósitos para diferentes usos. Além da contribuição ambiental, o aproveitamento de resíduos possibilita agregar valor aos painéis, que poderão ser utilizados na produção de móveis e em várias aplicações na construção civil.

\section{Referências}

ABREU, L. B. de et al. Avaliação de resíduos de painéis de madeira gerados por indústrias moveleiras para aproveitamento na confecção de pequenos objetos: estudo de caso. Ciência e Agrotecnologia, Lavras, v. 33, p. 1747-1751, 2009

ALBERTINI, S.; CARMO, L. F. do; PRADO FILHO, L. G. do. Utilização de serragem e bagaço de canade-açúcar para adsorção de cádmio. Ciência e Tecnologia de Alimentos, Campinas, v. 27, n. 1, p. 113-118, 2007.

ALVES, L. S.; SILVA, S. A. M. Confecção e avaliação de chapas de madeira aglomerada homogêneas empregando-se resíduos de empresas moveleiras de São José do Rio Preto e poliuretana derivada de óleo de mamona. In: ENCONTRO BRASILEIRO DE MADEIRAS E DE ESTRUTURAS DE MADEIRA, 14. Natal, 2014. Anais [...] Natal: EMBRAMEM, 2014.

ASSOCIAÇÃO BRASILEIRA DE NORMAS TÉCNICAS - ABNT. NBR 1004: resíduos sólidos: classificação. Rio de Janeiro, 2004.

ASSOCIAÇÃO BRASILEIRA DE NORMAS TÉCNICAS. NBR 14810-2: chapas de madeira aglomerada: requisitos. Rio de Janeiro, 2013.

ASSOCIAÇÃO BRASILEIRA DE NORMAS TÉCNICAS. NBR 14810: chapas de madeira aglomerada. Rio de Janeiro, 2006.

ASSOCIAÇÃO BRASILEIRA DE NORMAS TÉCNICAS. NBR 7217: agregados de determinação da composição granulométrica. Rio de Janeiro, 1987.

BARROS FILHO, R. M. de. Painéis aglomerados a base de bagaço de cana-de-açúcar e resinas uréia formaldeído e melamina formoldeído. 2007. $116 \mathrm{f}$. Tese (Doutorado) - Curso de Engenharia de Materiais, Rede Temática em Engenharia de Materiais, Ouro Preto, 2009.

BERTOLINI, M. S. de. Emprego de resíduos de Pinus sp tratado com preservante CCB na produção de chapas de partículas homogêneas utilizando resina poliuretana à base de mamona. 2011. $126 \mathrm{f}$. Dissertação (Mestrado em Engenharia de Materiais) - Universidade de São Paulo, São Carlos, 2011.

CARASCHI, J. C.; LEÃO, A. L.; COIADO CHAMMA, P. V. Avaliação de painéis produzidos a partir de resíduos sólidos para aplicação na arquitetura. Polímeros: Ciência e Tecnologia, São Paulo, v. 19, n. 1, p. 47-53, 2008.

CARDOSO, O. R. Preparação de resinas à base de óleo de mamona poliuretana e dietanolamina. 2005. 98 f. Dissertação (Mestrado em Química) - Centro de Ciências Exatas e da Terra, Universidade Federal do Rio Grande do Norte, Natal, 2007.

CERQUEIRA, P. H. A. de et al. Análise dos resíduos madeireiros gerados pelas serrarias do município de Eunápolis-BA. Floresta e Ambiente, Rio de Janeiro, v. 19, n. 4, p. 506-510, 2012. 
DIAS, A. A. Aplicação de resina poliuretana à base de mamona na fabricação de painéis de madeira aglomerada. Produtos Derivados de Madeira, São Paulo, p. 73-92, 2008.

FONTES, P. J. P. Auto-suficiência energética em serraria de pinus e aproveitamento dos resíduos. 1994. 140 f. Dissertação (Mestrado em Ciências Florestais) - Universidade Federal do Paraná, Curitiba, 1994.

GALVÃO, A. P. M.; JANKOWSKY, I. P. Secagem racional da madeira. São Paulo: Nobel, 1985.

IWAKIRI, S. et al. Resíduo de serrarias na produção de painéis de madeira aglomerada de eucalipto. Scientia Agraria, Curitiba, v. 1, n. 1-2, p. 23-28, 2000.

JESUS, J. M. H. de; CALIL JUNIOR, C. Estudo do adesivo poliuretano à base de mamona em madeira laminada colada (MLC). Madeira: Arquitetura e Engenharia, São Carlos, v. 3, n. 8, p. 1-47, maio 2002.

MARTON, A. Confecção e avaliação de chapas de madeira aglomerada com aproveitamento de resíduos de marcenaria industrial. 2014. 67 f. Dissertação (Mestrado em Engenharia Civil) Universidade Estadual Paulista, Ilha Solteira, 2014.

MENDES, R. F. et al. Painéis aglomerados produzidos com bagaço de cana em associação com madeira de eucalipto. Scientia Forestalis, Lavras, v. 38, n. 2, p. 285-295, jun. 2010.

MISAGIA, Z. M. V. et al. Materiais compósitos particulados em matriz epóxi reforçados com serragem, cimento e silicato de magnésio. Ambiente Construído, Porto Alegre, v. 13, n. 3, p. 285-302, set. 2013.

NARCISO, C. R. P. et al. Painéis aglomerados produzidos com resíduo de serraria. In: ENCONTRO BRASILEIRO EM MADEIRAS E EM ESTRUTURAS DE MADEIRA, 14., Natal, 2014. Anais [...] Natal: Moura Ramos, 2014.

NEGRÃO, W. H. et al. Painéis aglomerados fabricados com mistura de partículas de madeiras tropicais. Ambiente Construído, Porto Alegre, v. 14, n. 3, p.103-112, set. 2014.

PEDRESCHI, Ricardo. Aproveitamento de bagaço de cana da indústria sucroalcooleira na produção de painéis de aglomerados. 2009. 61 f. Tese (Doutorado em Ciência e Tecnologia da Madeira) - Universidade Federal de Lavras, Lavras, 2009.

SANCHEZ, E. M. S. et al. Compósito de resina de poliéster insaturado com bagaço de cana-de-açúcar: influência do tratamento das fibras nas propriedades. Polímeros, São Carlos, v. 20, n. 3, p. 194-200, 2010.

SILVA, S. A. M. da et al. Strength properties of medium density fiberboards (MDF) manufactured with Pinus elliottii wood and polyurethane resin dweived from castor oil. Scientific Academic Publishing, v. 1, n. 3, p. 7-14, May 2013.

SOARES, S. S. et al. Valorização do bagaço de cana-de-açúcar na produção de painéis aglomerados de baixa densidade. Brazilian Journal of Wood Science, Pelotas, p. 64-73, maio 2017.

TITA, S. P. S.; PAIVA, J. M. F. de; FROLLINI, E. Resistência ao impacto e outras propriedades de compósitos lignocelulósicos: matrizes termofixas fenólicas reforçadas com fibras de bagaço de cana-deaçúcar. Polímeros, São Carlos, v. 12, n. 4, p. 228-239, 2002.

Bruna Bessa Rocha Yano

Faculdade de Engenharia | Universidade do Oeste Paulista | Rodovia Raposo Tavares, km 572, Limoeiro | Presidente Prudente - SP - Brasil | CEP 19067-175 | Tel.: (18) 3229-2016 | E-mail: brunabessa@unoeste.br

Sérgio Augusto Mello da Silva

Departamento de Engenharia Civil, Faculdade de Engenharia | Universidade Estadual Paulista | Alameda Bahia, 550 | Ilha Solteira - SP Brasil | CEP 15385-000 | Tel.: (18) 3743-1902 | E-mail: sergio.mello@unesp.br

\section{Ambiente Construído}

Revista da Associação Nacional de Tecnologia do Ambiente Construído Av. Osvaldo Aranha, $99-3^{\circ}$ andar, Centro

Porto Alegre - RS - Brasil CEP $90035-190$

Telefone: +55 (51) 3308-4084

Fax: +55 (51) 3308-4054

www.seer.ufrgs.br/ambienteconstruido

E-mail: ambienteconstruido@ufrgs.br 